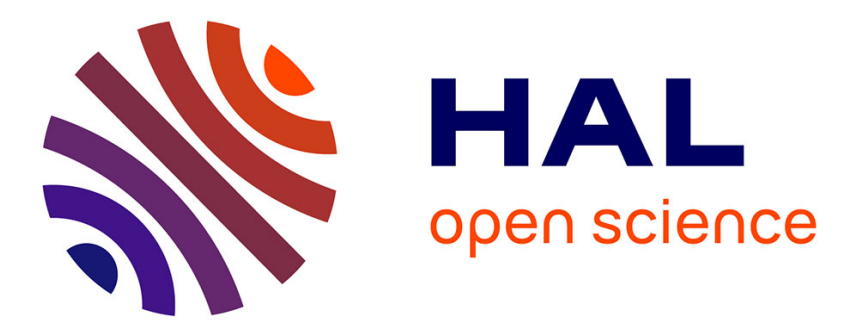

\title{
Trends in HIV testing and recording of HIV status in the UK primary care setting: a retrospective cohort study 1995-2005.
}

Hannah E R Hale, Catherine H Mercer, Greta Rait, Matthew Hamill, Valerie

Delpech, Gwenda Hughes, Gary Brook, Timothy Williams, Anne M Johnson, Surinder Singh, et al.

\section{To cite this version:}

Hannah E R Hale, Catherine H Mercer, Greta Rait, Matthew Hamill, Valerie Delpech, et al.. Trends in HIV testing and recording of HIV status in the UK primary care setting: a retrospective cohort study 1995-2005.. Sexually Transmitted Infections, 2009, 85 (7), pp.520. 10.1136/sti.2008.034801 . hal-00552805

\section{HAL Id: hal-00552805 https://hal.science/hal-00552805}

Submitted on 6 Jan 2011

HAL is a multi-disciplinary open access archive for the deposit and dissemination of scientific research documents, whether they are published or not. The documents may come from teaching and research institutions in France or abroad, or from public or private research centers.
L'archive ouverte pluridisciplinaire HAL, est destinée au dépôt et à la diffusion de documents scientifiques de niveau recherche, publiés ou non, émanant des établissements d'enseignement et de recherche français ou étrangers, des laboratoires publics ou privés. 


\title{
Trends in HIV testing and recording of HIV status in the UK primary care setting: a retrospective cohort study 1995-2005.
}

\author{
Hannah ER Evans, \\ Research Fellow, \\ Centre for Sexual Health and HIV Research, Research Department of Infection \& Population \\ Health, University College London, London WC1E 6JB, UK
}

Catherine H Mercer,

Senior Research Fellow,

Centre for Sexual Health and HIV Research, Research Department of Infection \& Population

Health, University College London, London WC1E 6JB, UK

Greta Rait,

Senior Lecturer in Primary Care,

Research Department of Primary Care \& Population Health, Royal Free Campus, University

College London, London NW3 2PF, UK

Matthew Hamill,

Research Fellow,

Centre for Clinical Vaccinology and Tropical Medicine, University of Oxford, OX3 7LJ, UK

Valerie Delpech,

Consultant Epidemiologist,

Centre for Infections, Health Protection Agency, London, NW9 5HT, UK

Gwenda Hughes,

Consultant Epidemiologist,

Centre for Infections, Health Protection Agency, London, NW9 5HT, UK

M Gary Brook,

Consultant in Genitourinary Medicine,

Patrick Clements Clinic, North West London Hospitals NHS Trust, London NW10 7NS 
Tim Williams,

Director of Research Services,

GPRD, Medicines and Healthcare Regulatory Agency, London SW8 5NG, UK

Anne M Johnson,

Research Department of Infection \& Population Health, Royal Free Campus, University College

London, London NW3 2PF, UK

Surinder Singh,

Senior Lecturer in General Practice,

Research Department of Primary Care \& Population Health, Royal Free Campus, University

College London, London NW3 2PF, UK

Irene Petersen,

Senior Research Fellow,

Research Department of Primary Care \& Population Health, Royal Free Campus, University

College London, London NW3 2PF, UK

Tim Chadborn,

Senior Scientist,

Centre for Infections, Health Protection Agency, London, NW9 5HT, UK

Jackie A Cassell

Professor of Primary Care Epidemiology,

Brighton and Sussex Medical School, Mayfield House, University of Brighton, Falmer, Brighton

BN1 9PH, UK.

Correspondence to J A Cassell j.cassell@bsms.ac.uk

Word count: Abstract 250 words

Main text: 2,979 words

Keywords: Primary care, HIV, HIV testing, surveillance 


\begin{abstract}
Objectives To provide nationally representative data on trends in HIV testing in primary care, and to estimate the proportion of diagnosed HIV positive individuals known to general practitioners (GPs).
\end{abstract}

Methods We undertook a retrospective cohort study between 1995-2005 of all general practices contributing data to the United Kingdom General Practice Research Database (GPRD), and data on persons accessing HIV care (Survey of Prevalent HIV Infections Diagnosed). We identified all practice-registered patients where an HIV test or HIV positive status is recorded in their general practice records. HIV testing in primary care, and prevalence of recorded HIV positive status in primary care were estimated.

Results Despite 11-fold increases in male testing, and 19-fold increases in non-pregnant female testing between 1995 and 2005, HIV testing rates remained low in 2005 at 71.3 and 61.2 tests per 100,000 person years for males and females respectively, peaking at 162.5 and 173.8 per 100,000 person years at 25-34 years of age. Inclusion of antenatal tests yielded a 129 fold increase in women over the 10 year period. In 2005, 50.7\% of HIV positive individuals had their diagnosis recorded, with a lower proportion in London (41.8\%) than outside the capital (60.1\%).

Conclusion HIV testing rates in primary care remain low. Normalisation of HIV testing and recording in primary care in antenatal testing has not been accompanied by a step change in wider HIV testing practice. Recording of HIV positive status by general practitioners (GPs) remains low, and GPs may be unaware of HIV-related morbidity or potential drug interactions. 


\section{INTRODUCTION}

HIV prevalence has increased in the UK over the last decade, with an estimated 73,000 individuals living with HIV by 2006, of whom 21,000 remained undiagnosed.(1) HIV patients' medical care has historically been managed by stand alone HIV specialist services, of which the larger provide some primary care services.(2) The number of HIV positive individuals requiring these services has increased three-fold since the mid-1990s as a consequence of new diagnoses and improved survival following the introduction of Highly Active Antiretroviral Therapy (HAART) around 1996.(1) While HIV services can ensure a high quality of HIV care for diagnosed individuals, GPs report anecdotally that overall clinical care may be compromised where a general practitioner is unaware of their patient's HIV status and other treatments.(3) There is evidence that close liaison between specialist HIV services and primary care can shorten admissions and improve the standard of health care in this group generally.(4)

Primary care remains a relatively under-utilised resource for the delivery of sexual health services other than contraception. England's National Strategy for Sexual Health and HIV proposes enhancement of sexual health services in general practice, including HIV testing, in order to reduce high mortality rates amongst individuals diagnosed late, and to reduce transmission associated with undiagnosed infection.(5) Universal offer of HIV testing to pregnant women began in 2000,(6) as it became clear that neonatal transmission is preventable, and uptake of antenatal testing practitioner-dependent.(7;8) While the success of this policy demonstrated the feasibility of HIV testing in a non-specialist setting,(9) no framework existed for delivering HIV testing in the wider population until recent recommendations for testing in primary care, and in other health settings.(10;11) Many patients diagnosed with acute(12) and established(13) HIV infection consult prior to diagnosis in primary care, often missing opportunities for earlier diagnosis.

In this study we aimed to provide the first nationally representative estimates of testing rates and recording of positive HIV status in primary care.

\section{METHODS}

Briefly, HIV testing rates and prevalence of recorded HIV in primary care were estimated using disaggregated data from a large primary care database (GPRD), broadly representative of the UK 
population and containing 2.8 million current patients in 2005. Incidence of HIV testing in males, and females, with and without antenatal screening was estimated. The prevalence of recorded HIV positive status in the GPRD was compared with a denominator of all HIV positive individuals reported to the surveillance dataset SOPHID (Survey of Prevalent HIV Diagnosed). This allowed us to estimate the proportion of all HIV positive individuals whose status was coded in their general practice record.

\section{Population and sampling}

The General Practice Research Database (GPRD) is a large anonymised primary care database derived from computerised clinical records produced during consultations in primary care. It contains anonymised data on 4.7\% (2.8 million in 2005) of the UK population. The Medicines and Healthcare Regulatory Agency (MHRA) holds the licence for the database and undertakes checks on the quality and completeness of data, which have been collected continuously since 1988. The GPRD is broadly demographically representative of the UK population, though there is a slight under-representation of inner London and Scotland. It has been used and validated for many pharmacoepidemiological, epidemiological and public health uses,(14) with a denominator of 296,098 person years of observation available to us for 2005. GPs enter medical diagnoses and symptoms using Read codes(15) or the similar but now superseded OXMIS (Oxford Medical Information Systems) codes. Read and Oxmis codes are alphanumeric hierarchical codes which have an associated text description, which are used to summarise information on diagnoses, symptoms, examination and referral in UK primary care in coded form. Their scope is more diverse than ICD-10 disease codes and some are ambiguous (e.g. "chlamydia") or nonspecific ("unspecified chronic viral infection"). In addition investigations, prescription data, and consultation data, age, gender, and Strategic Health Authority (SHA) of residence are recorded for each registered individual.

Practice level quintiles of Index of Multiple Deprivation for 2004 (IMD 2004) score were used as a proxy for the level of deprivation but ethnicity data were not available. Individual level linkage to other datasets was not available. 
We classified GPRD practices as rural or urban at super output area level (a small area geographic boundary) in England, Wales and Northern Ireland, and by NHS region in Scotland, using data from national statistics providers.

\section{Definitions of HIV testing and recorded HIV positive status}

33 codes were identified denoting a definite HIV test (Web Appendix 1) and 61 codes referring to HIV status, of which 56 codes denote a definite HIV positive status (see Web Appendix 2 for details). Individuals who had any medical code recorded in the GPRD denoting definite HIV positive status were subsequently defined as having recorded HIV positive status. An HIV test was considered to be "antenatal" if it occurred within six months of any medical code indicating a current pregnancy.

\section{Estimation of HIV testing rate in primary care}

We estimated the incidence of HIV testing during the time period 1995-2005 for males and females, including and excluding antenatal tests, using the GPRD registered population as denominator for person years at risk. Survival analysis was used to calculate person-years-ofexposure at risk of HIV testing. Poisson regression was used to calculate $95 \%$ confidence intervals (CI) and incidence rate ratios (IRR). Testing rates (excluding antenatal tests) were estimated by age group, gender, SHA, IMD and rural/urban category, and area of residence (London vs outside London) for 2005.

We restricted counts of patients' HIV test records to at most one test in any 90 day period. HIV test events are often duplicated in the GPRD due to the nature of data recording in general practice. For example, a patient may have an HIV test in general practice recorded in their medical records, while the corresponding laboratory test result may be recorded in their test records two weeks later. In addition, current surveillance from specialist clinics reports only one test in each 3 month period.(1) This approach also allows for one test only within the "window period" of 90 days after exposure to HIV, which can be regarded as a single episode of testing. We have therefore used the same definition of a 3 month period to allow for comparisons with other work. (Our data show that in 2005, 5.4\% of all male and $2.2 \%$ of all female tests were recorded within this 90 day period, with little evidence of change over time). 
Recorded HIV positive individuals were removed from the denominator for HIV testing incidence calculations, as they are no longer "at-risk" of HIV infection or testing.

\section{Estimating the prevalence of $\mathrm{HIV}$ recorded in primary care}

Prevalence of recorded HIV in primary care was calculated for the years 1995-2005 for males and females with a more detailed breakdown by age and demographic characteristics for 2005 only. The proportion of all diagnosed cases recorded in the GPRD was estimated by comparing recorded prevalence in the GPRD population as numerator, with age and sex-specific reports to the SOPHID surveillance system (see below) as denominator.

In the GPRD, prevalence of recorded HIV infections in general practice was calculated using the number of patients registered as at 30th June (mid-year) as denominator. HIV infection is most commonly diagnosed in genito-urinary medicine (GUM clinics) or elsewhere in secondary care settings, after which HIV positive patients may or may not inform their GP.(16) Practice software allows separate recording of the date of a diagnosis, and the date of a first consultation relating to that diagnosis. Therefore the GPRD patient record may in some cases give two different dates for first HIV diagnosis: an 'event date', (e.g. the date on which the diagnosis was made elsewhere) which could precede the 'consultation date' (e.g. date of first consultation in primary care when HIV was discussed and recorded by the GP). For this analysis we used the first date on which HIV positivity was recorded $\mathrm{n}$ the primary care record.

The Survey of Prevalent HIV Infections Diagnosed (SOPHID) is an annual survey of all persons attending at least once for HIV care in specialist services across the UK and represents the best available estimate of the diagnosed prevalence of HIV in the UK.(17) It was used as the denominator from which to estimate the proportion of HIV cases recorded in the primary care record. Individual anonymised data are collected and analysed by the Health Protection Agency. Mid-year population estimates were obtained from the UK's Office of National Statistics (ONS) as the denominator for UK HIV prevalence estimates.

\section{Other}

For all analyses we defined the population of London as the five pre-2006 Strategic Health Authorities (SHAs), with all other UK regions classed as outside the capital, using data provided by the Office for National Statistics . 
Data analysis was performed using STATA (version 9.0). 


\section{RESULTS}

A total of 13.8 million person years of observation was available for males and 13.9 million for females. We identified 28,447 HIV tests in the GPRD during the study period 1995-2005. In 1995, 147 males and 45 females contributing data were recorded as HIV positive by the end of the year, and by 2005 this had risen to 776 and 413 .

\section{HIV testing in primary care}

Figure 1 summarises trends in HIV testing during the study period, with rates for the age groups 16-44 and non-antenatal testing shown separately. The period 1995-2005 saw an 11-fold increase in HIV testing rates among males, and a 129-fold increase in all women, reaching 514.5 per 100,000 women in 2005. However when antenatal tests were excluded, the increase among females reduced to 19-fold, and annual testing rates remained lower in females (61.2 per100,000 person-years) than in males (71.3 per100,000 person-years) in 2005. Exact numbers are given in Web Table 1.

Tables 1a and 1b show HIV testing by age, sex and demographic characteristics. In 2005, testing incidence (excluding antenatal) among patients living in London was more than double the rate seen elsewhere in the UK in both sexes (IRR= 2.1 (95\% CI 1.8, 2.4) and 2.2 (95\% CI 1.9, 2.6) for males and females, respectively. Outside London, testing rates were highest among adults aged 25-34 in both sexes (156.2 and 162.3 per 100,000 person years respectively). However in London testing was higher among adults aged 35-44 among both males and females (263.9 and 271.9 per 100,000 person years respectively). Among females, testing varied by level of deprivation with more testing in deprived settings. Individuals in non-urban areas were less likely to test.

\section{Prevalence of recorded HIV positive status in primary care, and how it compares with SOPHID data}

Table 2 shows trends in the prevalence of recorded HIV positive status in the GPRD, separately and as a proportion of SOPHID cases. An estimated 50.7\% (95\% CI 47.9-53.7\%) of HIV positive individuals had their status recorded in coded form in their primary care record in 2005, a proportion which changed little in the period between 1995 and 2005. Prevalence of HIV recorded in primary care increased in parallel with HIV diagnosed prevalence in SOPHID, but the proportion of diagnosed individuals having their HIV status recorded in primary care remained relatively constant. Throughout, recording remained lower in London than elsewhere, with the 
proportion declining to $41.8 \%$ in 2005 , by contrast with an increase to $60.1 \%$ outside the capital city.

Table 3 shows estimates of recorded positive status by age, sex and demographic characteristics in 2005. Recording was less likely for men and women aged 25-34 (36.4\% males and 40.0\% females), than older adults (61.0\% males and $73.2 \%$ females over 45 ) or children under 16 (Table $3)$. 


\section{Discussion}

HIV testing increased substantially, 11 fold in males and 19 fold in non-pregnant females, in the primary care setting between 1995 and 2005. These increases were small in comparison with increased antenatal testing.

Only half of all HIV positive individuals are recorded as such in the primary care records. This proportion remained consistently lower in London than elsewhere, and did not change despite rising prevalence over the decade.

This study provides the first nationally representative estimates of testing rates and recording of positive HIV status in primary care. Only a small proportion of HIV tests have traditionally been taken in primary care. Chadborn and colleagues estimated that $6.6 \%$ of tests in London and $13.0 \%$ of tests outside London were taken in this setting, in the decade to 2000.(16) A number of studies have confirmed that many late presenters, who face increased mortality, have consulted in primary care in the 12 months prior to diagnosis. $(18 ; 19)$ Our data demonstrate that while a large number of antenatal HIV tests are routinely documented in primary care, expansion of antenatal testing has not been accompanied by a wider step change in testing patterns.

The steady rates of recording in primary care, during a period in which HAART has transformed prognosis and increased prevalence are surprising, particularly in London. Lower recording in London may relate to lower disclosure rates, to patients' difficulties in accessing primary care, or fear of disclosure among migrants who continue to form a high proportion of all HIV cases and are often resident in London.(1) However, earlier studies demonstrated high rates of GP registration and consultation even among these vulnerable groups, $(20 ; 21)$ and this does not fully explain the low recorded rates seen in the capital. No data are available on patterns of computerised coding practice for HIV in primary care, and these may have changed over time.

While benefitting from nationally representative data, our study has a number of limitations. We may be underestimating HIV testing and disclosure in primary care, particularly in earlier years before widespread implementation of electronically recorded laboratory results, which are more

likely to lead to a recorded test code than paper results. Antenatal testing may also be underestimated, since women can be tested elsewhere (e.g. a hospital or community antenatal 
visits) and negative results may not appear in the primary care record. We have not sought to match our estimates to antenatal HIV testing surveillance for this reason. Not all cases of HIV disclosed to GPs will be coded as such in the notes - "euphemism" codes such as "chronic viral illness" may be used, information may be hidden in non-coded free text, or not recorded at all. Recorded HIV diagnoses are a combination of HIV incidence and prevalence, with patients registering, presenting and disclosing to GPs, and then GPs entering this onto the clinical record Anecdotal information sought from general practitioners during the study suggests that recording practice has been variable, but that precise coding is more likely in recent years.

We also cannot reliably determine a true "incident" date of HIV diagnosis, nor which cases were diagnosed in primary care. Initial HIV positive tests from a laboratory are normally notified to a GP by telephone for confirmatory testing (which may then be conducted in GUM settings). These do not automatically generate a coded entry, and so cannot be distinguished from cases diagnosed elsewhere.

The lack of ethnicity data in the GPRD means that we cannot reliably interpret the relationship between our findings and recent demographic changes in the UK HIV epidemic. We were not able to explore the extent to which non-recording is concentrated in different ethnic groups, and in particular among black Africans who may have concerns about migration and health care entitlements, which discourage disclosure to the GP. Sexual orientation may not be known to the GP and we are unable to estimate recording or testing rates among men who have sex with men from our data. Finally, biases introduced by under-representation of London practices cannot be accurately assessed.

It is increasingly recognised in UK policy that normalisation of HIV testing in primary care, on the scale already seen in the context of antenatal care, will be required in order to reduce the pool of undiagnosed prevalence,(22;23) and national guidelines aimed at achieving this have recently been published.(10) The CDC in the United States recommends opt out HIV testing for all adults attending any healthcare facility, aimed at decreasing late presentation with symptomatic HIV/AIDS and onward transmission.(24) Given that a third of HIV infected individuals are undiagnosed, and a third of all those newly diagnosed present late in the course of their infection, $(1 ; 25)$, there is a need to expand HIV testing in primary care as well as other healthcare settings. 
Surveillance of HIV testing in the primary care setting is essential to measure uptake and to ensure its feasibility, acceptability and cost-effectiveness. Our data demonstrate the feasibility of using large primary care databases to monitor testing rates at national level. Further work is needed on the mechanisms required to deliver increased HIV testing in primary care. Detailed studies that explore barriers to the recording of positive HIV status in primary care and its relationship to the delivery of care to HIV positive individuals could contribute to the planning of services for this group.

\section{Competing interest statement}

All authors declare that the answer to the questions on your competing interest form are all No and therefore have nothing to declare.

\section{Guarantor}

Jackie A Cassell

\section{Contributors.}

JC had the original idea for the study, and developed a detailed proposal for funding alongside CM, GR, MGB, VD, AMJ, SS, GH, TW and IP. Code lists were developed and refined by all members of the team, particularly MH, MGB, GH and JC. HE undertook all analyses under the supervision of CM and JC, with input from all other members of the team. VD and TC led the provision, use, analysis and interpretation of SOPHID data. HE wrote the first draft and all authors contributed to and commented on subsequent versions.

\section{Ethics approval}

No study specific ethical approval was required. The protocol was submitted to the Independent Scientific Advisory Committee for the GPRD, who approved it under delegated authority.

\section{Funding}

This work was funded by the Medical Research Council, with funding allocated from the Health Departments, under the aegis of the MRC/UK Health Departments Sexual Health and HIV Research Strategy Committee. 
Statement of independence from funders: The Medical Research Council has had no role in the collection, analysis, and interpretation of data; in the writing of the report; or in the decision to submit the paper publication. The views expressed are those of the authors and not necessarily those of the MRC or the Health Departments.

\section{Copyright statement}

The Corresponding Author has the right to grant on behalf of all authors and does grant on behalf of all authors, an exclusive licence (or non exclusive for government employees) on a worldwide basis to the BMJ Publishing Group Ltd to permit this article (if accepted) to be published in STI and any other BMJPGL products and sub-licences such use and exploit all subsidiary rights, as set out in our licence http://sti.bmjjournals.com/ifora/licence.pdf)

\section{Key points.}

- Little is known about HIV testing in primary care, or the extent of disclosure of HIV positivity to GPs, despite the importance of early diagnosis.

- HIV testing rates in primary care increased slowly, but remained low in the decade to 2005, and were highest in young adults.

- GPs test for HIV more in London and other urban areas.

- Less than half of all HIV positive individuals are recorded as such by their GPs, and with a lower proportion in London where HIV is concentrated. 
Figure 1: HIV testing in general practice, all ages and ages 16-44 years by gender ,and antenatal testing rates among females 16-44 between 1995-2005 with 95\% Cl.

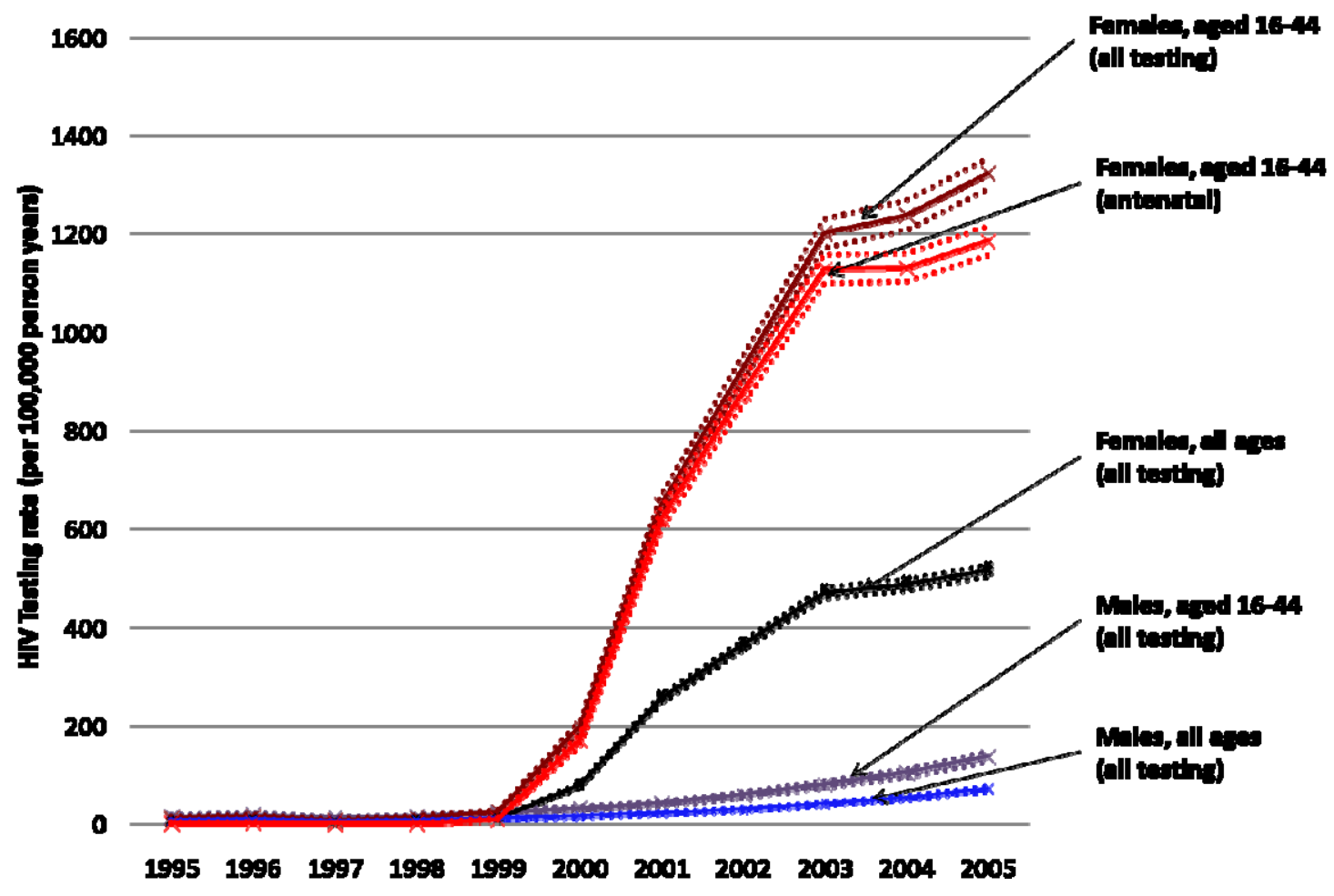


Web Table 1: Rates (per 100,000 person-years) of HIV testing recorded in general practice among a) all males b) all females and c) non-antenatal testing (females only) 1995-2005.

\begin{tabular}{lrcccccccccccc}
\hline & Year: & $\mathbf{1 9 9 5}$ & $\mathbf{1 9 9 6}$ & $\mathbf{1 9 9 7}$ & $\mathbf{1 9 9 8}$ & $\mathbf{1 9 9 9}$ & $\mathbf{2 0 0 0}$ & $\mathbf{2 0 0 1}$ & $\mathbf{2 0 0 2}$ & $\mathbf{2 0 0 3}$ & $\mathbf{2 0 0 4}$ & $\mathbf{2 0 0 5}$ \\
a) All males: & & & & & & & & & & \\
& Number of tests & 55 & 74 & 52 & 79 & 137 & 211 & 315 & 435 & 594 & 777 & 1044 \\
& Rate & 6.68 & 8.24 & 5.22 & 7.29 & 11.27 & 15.95 & 22.28 & 30.14 & 41.07 & 52.81 & 71.29 \\
& $95 \%$ CI lower bound & 5.12 & 6.56 & 3.98 & 5.85 & 9.53 & 13.94 & 19.95 & 27.44 & 37.90 & 49.22 & 67.09 \\
& $95 \%$ CI upper bound & 8.69 & 10.35 & 6.85 & 9.09 & 13.32 & 18.25 & 24.88 & 33.11 & 44.51 & 56.66 & 75.75 \\
\hline
\end{tabular}

b) All females:

\begin{tabular}{rccccccccccc} 
Number of tests & 34 & 55 & 27 & 61 & 129 & 1069 & 3705 & 5358 & 6932 & 7304 & 7699 \\
Rate & 3.99 & 5.92 & 2.62 & 5.46 & 10.29 & 78.53 & 255.45 & 363.08 & 469.69 & 486.55 & 514.46 \\
$95 \%$ CI lower bound & 2.85 & 4.55 & 1.80 & 4.25 & 8.66 & 73.96 & 247.35 & 353.48 & 458.76 & 475.52 & 503.10 \\
$95 \%$ CI upper bound & 5.59 & 7.71 & 3.83 & 7.01 & 12.22 & 83.38 & 263.81 & 372.93 & 480.88 & 497.84 & 526.08 \\
\hline
\end{tabular}

c) Non-antenatal testing (females only):

\begin{tabular}{rcccccccccccc} 
Number of tests & 28 & 46 & 23 & 54 & 84 & 167 & 203 & 326 & 479 & 700 & 916 \\
Rate & 3.29 & 4.95 & 2.24 & 4.83 & 6.70 & 12.27 & 14.00 & 22.09 & 32.46 & 46.63 & 61.21 \\
$95 \%$ CI lower bound & 2.18 & 3.63 & 1.42 & 3.63 & 5.34 & 10.48 & 12.14 & 19.76 & 29.61 & 43.24 & 57.31 \\
$95 \%$ CI upper bound & 4.75 & 6.61 & 3.36 & 6.30 & 8.29 & 14.28 & 16.06 & 24.62 & 35.50 & 50.22 & 65.30 \\
\hline
\end{tabular}


Table 1a): Rates (per 100,000 person-years) of HIV testing recorded in general practice in 2005 by age group, deprivation level and rural/urban indicators, stratified by London $v s$. outside of London-Males

London

All

Level of

deprivation:

Quintile 1

(Least deprived)

Quintiles 2-4

Quintile 5

(Most deprived)

$233 \quad 131.22$

(per 100,000 person-year)

IRR $(95 \%$ CI $)$

Rurallurban

indicator:

Urban

Intermediate

Rural

$\begin{array}{rr}24 & 141.15 \\ 168 & 127.00 \\ 41 & 144.95\end{array}$

1
0.90

0.90
$0.59,1.38$
1.03

1.03

$(0.62,1.70)$

$p=0.703$

229

132.26

1
0.68

$(0.25,1.84)$

$\mathrm{p}=0.450$

N\A*

90.36

$\mathrm{N} \backslash \mathrm{A}$

Age group:

$<16$

16-19

20-24

25-34

35-44

$45+$

$$
1.61
$$

$(0.96,2.71)$

4.54

$(3.18,6.48)$

7.45

$(5.69,9.77)$

$$
6.32
$$

(4.84,8.26)

1.69

(1.28,2.24)

$\mathrm{p}<0.001$

92.59
Outside Capital, UK

\section{Rate}

N (per 100,000 person-year)

IRR (95\% CI)

63.02

175

456

65.26

179

63.41

$\mathrm{p}=0.322$

676

68.38

42.64

50.90

$\mathrm{p}<0.001$

42

68

21.05

1
275

ral.

$\begin{array}{cc}18 & 33.97 \\ 55 & 95.53 \\ 228 & 156.20 \\ 258 & 133.10 \\ 183 & 35.64\end{array}$

$(1.03,7.33)$

5.08

(2.38,10.85)

6.03

(3.24,11.23)

8.41

(4.60,15.37)

2.95

$(1.58,5.51)$

$\mathrm{p}<0.001$ 
Table 1b): Rates (per 100,000 person-years) of HIV testing recorded in general practice in 2005 by age group, deprivation level and rural/urban indicators, stratified by London $v$ s. outside of London - Females, excluding antenatal tests.

London

covariate

All

Level of

deprivation:

Quintile 1

(Least deprived)

Quintiles 2-4

Quintile 5

(Most deprived)

Rurallurban

indicator:

Urban

Intermediate

Rural

Age group:

$<16$

16-19

20-24

25-34

$35-44$
Rate

$\mathrm{N} \quad$ (per 100,000 person-year)

IRR $(95 \%$ CI $)$

p-value

$$
117.64
$$

212

(102.82, 134.59)

-- - - -

135

411

158

182.96

$1.59(0.96,2.66)$

$\mathrm{p}=0.004$

587

90

27

$\mathrm{N} \backslash \mathrm{A}$

N\A N\A

$\mathrm{N} \backslash \mathrm{A}$

16.44

59.34

246.27

226.96

271.90
1
3.61

$(1.02,12.79)$

14.98

$(6.19,36.29)$

$$
13.81
$$

$(6.01,31.74)$

16.54

$(7.22,37.91)$
Rate (per 100,000 person-

year)

IRR $(95 \%$ CI $)$

53.48

$(49.67,57.58)$

43.15

57.18

55.51

1.32

$(1.09,1.61)$

1.29

$(1.02,1.62)$

$\mathrm{p}=0.01 \mathrm{t}$

58.14

40.60

31.77

0.70

$(0.56,0.87)$

0.55

$(0.37,0.80)$

21.40

2.54

(1.62,3.98)

5.52

$(3.93,7.74)$

7.58

$(5.76,9.99)$

4.91

(3.71,6.51) 
$45+\quad 21 \quad 32.79 \quad 1.99(0.81,4.94) \quad \mathrm{p}<0.001$

* N/A signifies "not applicable", since there are no areas in London classified as rural. 
Table 2: Prevalence of diagnosed HIV (SOPHID), HIV recorded in primary care (per 100,000 persons), and the proportion of HIV recorded in primary care, between 1995-2005 -a) London and b) outside London

\begin{tabular}{|c|c|c|c|c|c|c|c|c|c|c|c|}
\hline Year: & 1995 & 1996 & 1997 & 1998 & 1999 & 2000 & 2001 & 2002 & 2003 & 2004 & 2005 \\
\hline \multicolumn{12}{|l|}{ a) London } \\
\hline Numbers in SOPHID & NA & 8234 & 9252 & 10277 & 11531 & 12917 & 14505 & 16544 & 18824 & 20387 & 22228 \\
\hline Prevalence of diagnosed HIV (SOPHID) per 100,000 persons & NA & 118.06 & 131.90 & 145.44 & 161.19 & 178.49 & 198.10 & 224.44 & 254.79 & 274.45 & 295.68 \\
\hline Numbers in GPRD & 1 & 5 & 11 & 18 & 41 & 179 & 304 & 643 & 763 & 937 & 979 \\
\hline \multicolumn{12}{|l|}{ Prevalence of HIV recorded in primary care (GPRD) per } \\
\hline 100,000 persons & 43.12 & 42.24 & 47.92 & 52.50 & 60.10 & 84.56 & 78.66 & 88.04 & 101.40 & 113.48 & 123.43 \\
\hline $95 \%$ CI, lower bound & 32.49 & 31.91 & 38.73 & 43.23 & 51.35 & 74.63 & 69.64 & 78.86 & 91.49 & 102.97 & 112.12 \\
\hline $95 \%$ CI, upper bound & 56.13 & 54.86 & 58.64 & 63.17 & 69.91 & 95.44 & 88.53 & 97.99 & 112.10 & 124.77 & 135.58 \\
\hline$\%$ of $\mathrm{HIV}+$ patients whose status is recorded in general practice & NA & $35.78 \%$ & $36.33 \%$ & $36.10 \%$ & $37.29 \%$ & $47.37 \%$ & $39.71 \%$ & $39.23 \%$ & $39.80 \%$ & $41.35 \%$ & $41.75 \%$ \\
\hline $95 \%$ CI, lower bound & $N A$ & $27.03 \%$ & $29.36 \%$ & $29.72 \%$ & $31.86 \%$ & $41.81 \%$ & $35.15 \%$ & $35.14 \%$ & $35.91 \%$ & $37.52 \%$ & $37.92 \%$ \\
\hline 95\% CI, upper bound & $N A$ & $46.47 \%$ & $44.46 \%$ & $43.44 \%$ & $43.37 \%$ & $53.47 \%$ & $44.69 \%$ & $43.66 \%$ & $44.00 \%$ & $45.46 \%$ & $45.85 \%$ \\
\hline \multicolumn{12}{|l|}{ b) Outside London } \\
\hline Numbers in SOPHID & NA & 6629 & 6818 & 7746 & 8856 & 10107 & 12096 & 15258 & 18274 & 21790 & 25116 \\
\hline Prevalence of diagnosed HIV (SOPHID) per 100,000 persons & NA & 12.95 & 13.29 & 15.07 & 17.19 & 19.57 & 23.36 & 29.37 & 35.03 & 41.58 & 47.67 \\
\hline Numbers in GPRD & 88 & 124 & 68 & 122 & 225 & 1101 & 3715 & 5146 & 6759 & 7137 & 7759 \\
\hline $\begin{array}{l}\text { Prevalence of HIV recorded in primary care (GPRD) per } \\
\text { per } 100,000 \text { persons }\end{array}$ & 8.90 & 8.99 & 9.43 & 9.36 & 10.81 & 10.66 & 12.57 & 14.79 & 18.43 & 23.06 & 28.65 \\
\hline $95 \%$ CI, lower bound & 7.47 & 7.62 & 8.08 & 8.07 & 9.48 & 9.38 & 11.22 & 13.33 & 16.80 & 21.25 & 26.64 \\
\hline 95\% CI, upper bound & 10.52 & 10.55 & 10.94 & 10.81 & 12.28 & 12.06 & 14.03 & 16.36 & 20.17 & 24.98 & 30.77 \\
\hline$\%$ of $\mathrm{HIV}+$ patients whose status is recorded in general practice & NA & $69.44 \%$ & $70.95 \%$ & $62.14 \%$ & $62.92 \%$ & $54.46 \%$ & $53.81 \%$ & $50.35 \%$ & $52.61 \%$ & $55.46 \%$ & $60.11 \%$ \\
\hline $95 \%$ CI, lower bound & NA & $58.81 \%$ & $60.77 \%$ & $53.53 \%$ & $55.17 \%$ & $47.94 \%$ & $48.06 \%$ & $45.39 \%$ & $47.96 \%$ & $51.10 \%$ & $55.89 \%$ \\
\hline $95 \%$ CI, upper bound & NA & $81.44 \%$ & $82.35 \%$ & $71.75 \%$ & $71.47 \%$ & $61.61 \%$ & $60.06 \%$ & $55.70 \%$ & $57.59 \%$ & $60.09 \%$ & $64.56 \%$ \\
\hline
\end{tabular}

Notes for Tables 2 and 3:

The denominator used for the prevalence of diagnosed HIV (from SOPHID) was the estimated population mid-year provided by the Office of National Statistics.

The denominator used for the prevalence of HIV recorded (GPRD) was the number of patients registered mid-year.

Due to old geography codes and poor quality of the data in 1995, prevalence by region is not shown for this year. 
Table 3: Prevalence of recorded diagnosed HIV in primary care (per 100,000 persons), and the estimated proportion of HIV recorded in primary care in 2005 -among a) males and b) females by age group.

\begin{tabular}{|c|c|c|c|c|c|c|}
\hline & Age (years), grouped: & $<16$ & 16-24 & 25-34 & $35-44$ & $45+$ \\
\hline \multicolumn{7}{|l|}{ a) Males } \\
\hline \multicolumn{4}{|c|}{$\begin{array}{l}\text { Number in SUPHID } \\
\text { Prevalence of diagnosed HIV (SOPHID) per } 100.000\end{array}$} & 6632 & 13588 & 9408 \\
\hline \multicolumn{7}{|c|}{ Prevalence of diagnosed HIV (SOPHID) per 100,000 } \\
\hline Number in GPRD & & 30 & 12 & 107 & 328 & 299 \\
\hline \multicolumn{7}{|c|}{ Prevalence of HIV recorded in primary care (GPRD) per } \\
\hline \multirow[t]{3}{*}{100,000 persons } & & 8.39 & 9.54 & 61.38 & 143.94 & 50.85 \\
\hline & $95 \%$ CI, lower bound & 5.66 & 4.93 & 50.31 & 128.78 & 45.25 \\
\hline & $95 \%$ CI, upper bound & 11.98 & 16.67 & 74.18 & 160.39 & 56.95 \\
\hline \multicolumn{7}{|c|}{$\%$ of HIV+ patients whose status is recorded in general } \\
\hline \multirow[t]{3}{*}{ practice } & & $79.08 \%$ & $39.26 \%$ & $36.40 \%$ & $48.50 \%$ & $61.10 \%$ \\
\hline & $95 \%$ CI, lower bound & $53.35 \%$ & $20.29 \%$ & $29.83 \%$ & $43.40 \%$ & $54.37 \%$ \\
\hline & $95 \%$ CI, upper bound & $112.89 \%$ & $68.59 \%$ & $43.99 \%$ & $54.05 \%$ & $68.43 \%$ \\
\hline \multicolumn{7}{|l|}{ b) Females } \\
\hline Number in SOPHID & & 636 & 1189 & 5967 & 6147 & 2264 \\
\hline \multicolumn{3}{|c|}{$\begin{array}{l}\text { Number in SOPHID } \\
\text { Prevalence of diagnosed HIV (SOPHID) per 100,000 }\end{array}$} & 34.27 & 150.55 & 131.72 & 17.88 \\
\hline Number in GPRD & & 25 & 23 & 108 & 172 & 85 \\
\hline \multicolumn{7}{|c|}{ Prevalence of HIV recorded in primary care (GPRD) per } \\
\hline 100,000 persons & & 7.53 & 18.42 & 60.21 & 77.51 & 13.08 \\
\hline & $95 \%$ CI, lower bound & 4.87 & 11.68 & 49.40 & 66.36 & 10.45 \\
\hline & 95\% CI, upper bound & 11.11 & 27.64 & 72.70 & 90.00 & 16.18 \\
\hline \multicolumn{7}{|c|}{$\%$ of HIV+ patients whose status is recorded in general } \\
\hline & $95 \%$ CI, lower bound & $43.28 \%$ & $34.08 \%$ & $32.81 \%$ & $50.38 \%$ & $58.46 \%$ \\
\hline & $95 \%$ CI, upper bound & $98.72 \%$ & $80.66 \%$ & $48.29 \%$ & $68.33 \%$ & $90.49 \%$ \\
\hline
\end{tabular}


Web Appendix 1: Read \& OXMIS codes denoting an HIV test used to identify patients who have ever had a HIV test recorded in primary care.

\begin{tabular}{|c|c|c|c|}
\hline Code & $\begin{array}{l}\text { READ/ } \\
\text { OXMIS }\end{array}$ & Code description & $\begin{array}{c}\text { Certainty of } \\
\text { HIV + test }\end{array}$ \\
\hline 6827.11 & READ & HIV screening & Definite \\
\hline 43C..00 & READ & HTLV-3 antibody test & Definite \\
\hline 43C..11 & READ & Aids antibody test & Definite \\
\hline 43C..12 & READ & Human immunodefic.viral test & Definite \\
\hline $43 \mathrm{C} 1.00$ & READ & Blood sent for HTLV-3 serology & Definite \\
\hline $43 \mathrm{C} 2.00$ & READ & HTLV-3 antibody negative & Definite \\
\hline $43 \mathrm{C} 2.11$ & READ & HIV negative & Definite \\
\hline $43 \mathrm{CZ} .00$ & READ & HTLV-3 antibody NOS & Definite \\
\hline $43 \mathrm{~d} 5.00$ & READ & HIV antibody/antigen (Duo) & Definite \\
\hline $43 \mathrm{~d} 6.00$ & READ & HTLV 1 antibody level & Ambiguous \\
\hline $43 \mathrm{dc} .00$ & READ & HTLV 2 antibody level & Ambiguous \\
\hline $43 \mathrm{~h} 2.00$ & READ & HIV 1 PCR & Definite \\
\hline $43 \mathrm{j} 7.00$ & READ & HIV 1 nucleic acid detection & Definite \\
\hline $43 \mathrm{~V} 1.00$ & READ & Absolute CD4 count & Definite \\
\hline 43VE.00 & READ & CD4/CD8 ratio & Definite \\
\hline $43 \mathrm{VH} .00$ & READ & Percentage CD4 count & Definite \\
\hline 43 Vo. 00 & READ & Absolute CD4 (T4 cells) count & Definite \\
\hline $43 \mathrm{Vp} .00$ & READ & Percentage CD4 (T4 cells) count & Definite \\
\hline $43 \mathrm{~W} 7.00$ & READ & HIV1 antibody level & Definite \\
\hline $43 \mathrm{~W} 8.00$ & READ & HIV2 antibody level & Definite \\
\hline $43 \mathrm{WK} .00$ & READ & Human immunodeficiency virus antibody level & Definite \\
\hline $4 \mathrm{~J} 34.00$ & READ & HIV viral load & Definite \\
\hline $4 \mathrm{~J} 35.00$ & READ & HIV p24 antigen level & Definite \\
\hline 4JDT.00 & READ & HIV serology & Definite \\
\hline 4JR7.00 & READ & HIV screening test & Definite \\
\hline $62 b . .00$ & READ & Antenatal HIV screening & Definite \\
\hline 6827.00 & READ & AIDS (HTLV-III) screening & Definite \\
\hline R109.00 & READ & [D]Laboratory evidence of human immunodefiency virus [HIV] & Definite \\
\hline ZV01800 & READ & [V]Human immunodeficiency virus - negative & Definite \\
\hline ZV73700 & READ & [V]Special screening exam for human immunodefiency virus & Definite \\
\hline L1111PV & OXMIS & HIV ANTIBOBY TEST POSITIVE & Definite \\
\hline L 153P & OXMIS & HTVL-AIDS-III ANTIBODY TEST POSITIVE & Definite \\
\hline L 153 & OXMIS & HTVL-AIDS-III ANTIBODY TEST & Definite \\
\hline L1111NE & OXMIS & HIV ANTIBODY TEST NEGATIVE & Definite \\
\hline $\mathrm{L} 153 \mathrm{~N}$ & OXMIS & HTVL-AIDS-III ANTIBODY TEST NEGATIVE & Definite \\
\hline 65VE.00 & READ & Notification of AIDS & Ambiguous \\
\hline $43 \mathrm{j} 8.00$ & READ & HTLV 1 nucleic acid detection & Ambiguous \\
\hline
\end{tabular}


Web Appendix 2: Read \& OXMIS codes denoting HIV positive status used to identify HIV positive patients who have their HIV positive status recorded in primary care.

\begin{tabular}{|c|c|c|c|}
\hline Code & $\begin{array}{c}\text { Read/ } \\
\text { OXMIS }\end{array}$ & Code description & $\begin{array}{l}\text { Certainty of } \\
\text { HIV+ status }\end{array}$ \\
\hline 65QA.00 & READ & AIDS carrier & Definite \\
\hline A789700 & READ & HIV disease resulting other ypes of non-Hodgkin's lymphoma & Definite \\
\hline A789800 & READ & HIV disease resulting in multiple malignant neoplasms & Definite \\
\hline A788.00 & READ & Acquired immune deficiency syndrome & Definite \\
\hline A788500 & READ & Human immunodeficiency virus with secondary infection & Definite \\
\hline A788X00 & READ & HIV disease resulting/unspcf infectious+parasitic disease & Definite \\
\hline A789200 & READ & HIV disease resulting in candidiasis & Definite \\
\hline A789500 & READ & HIV disease resulting in Kaposi's sarcoma & Definite \\
\hline AyuC100 & READ & [X]HIV disease resulting in other viral infections & Definite \\
\hline AyuC700 & READ & [X]HIV dis reslt/oth mal neopl/lymph,h'matopoetc+reltd tissu & Definite \\
\hline A788000 & READ & Acute human immunodeficiency virus infection & Definite \\
\hline A788100 & READ & Asymptomatic human immunodeficiency virus infection & Definite \\
\hline A789300 & READ & HIV disease resulting in Pneumocystis carinii pneumonia & Definite \\
\hline A789600 & READ & HIV disease resulting in Burkitt's lymphoma & Definite \\
\hline A798.00 & READ & Retrovirus infection & Definite \\
\hline AyuC200 & READ & [X]HIV disease resulting in other mycoses & Definite \\
\hline AyuCA00 & READ & [X]HIV disease resulting in multiple diseases CE & Definite \\
\hline A788U00 & READ & HIV disease result/haematological+immunologic abnorms,NEC & Definite \\
\hline A789.00 & READ & Human immunodef virus resulting in other disease & Definite \\
\hline AyuC000 & READ & [X]HIV disease resulting in other bacterial infections & Definite \\
\hline АyuC800 & READ & [X]HIV disease resulting in other malignant neoplasms & Definite \\
\hline 43C 3.11 & READ & HIV positive & Definite \\
\hline A788y00 & READ & Human immunodeficiency virus with other clinical findings & Definite \\
\hline $\mathrm{Eu} 02400$ & READ & [X]Dementia in human immunodef virus [HIV] disease & Definite \\
\hline ZV01A00 & READ & [V]Asymptomatic human immunodeficency virus infection status & Definite \\
\hline A789400 & READ & HIV disease resulting in multiple infections & Definite \\
\hline AyuC500 & READ & [X]HIV disease resulting/unspcf infectious+parasitic disease & Definite \\
\hline AyuC900 & READ & [X]HIV disease resulting in unspecified malignant neoplasm & Definite \\
\hline AyuCC00 & READ & [X]HIV disease resulting in other specified conditions & Definite \\
\hline $43 \mathrm{C} 3.00$ & READ & HTLV-3 antibody positive & Definite \\
\hline A788W00 & READ & HIV disease resulting in unspecified malignant neoplasm & Definite \\
\hline A789X00 & READ & HIV dis reslt/oth mal neopl/lymph,h'matopoetc+ & Definite \\
\hline AyuC300 & READ & [X]HIV disease resulting in multiple infections & Definite \\
\hline AyuC400 & READ & [X]HIV disease resulting/other infectious+parasitic diseases & Definite \\
\hline АyuC600 & READ & [X]HIV disease resulting in other non-Hodgkin's lymphoma & Definite \\
\hline A788600 & READ & Human immunodeficiency virus with secondary cancers & Definite \\
\hline A788z00 & READ & Acquired human immunodeficiency virus infection syndrome NOS & Definite \\
\hline A789A00 & READ & HIV disease resulting in wasting syndrome & Definite \\
\hline 65VE.00 & READ & Notification of AIDS & Definite \\
\hline A788.11 & READ & Human immunodeficiency virus infection & Definite \\
\hline A788200 & READ & HIV infection with persistent generalised lymphadenopathy & Definite \\
\hline A788300 & READ & Human immunodeficiency virus with constitutional disease & Definite \\
\hline A788400 & READ & Human immunodeficiency virus with neurological disease & Definite \\
\hline
\end{tabular}


Web Appendix 2 (CONT'D): Read \& OXMIS codes denoting HIV positive status used to identify HIV positive patients who have their HIV positive status recorded in primary care.

\begin{tabular}{|c|c|c|c|}
\hline Code & $\begin{array}{c}\text { Read/ } \\
\text { OXMIS }\end{array}$ & Code description & $\begin{array}{l}\text { Certainty of } \\
\text { HIV+ status }\end{array}$ \\
\hline A788V00 & READ & HIV disease resulting in multiple diseases CE & Definite \\
\hline A789100 & READ & HIV disease resulting in cytomegaloviral disease & Definite \\
\hline AyuC.00 & READ & {$[\mathrm{X}]$ Human immunodeficiency virus disease } & Definite \\
\hline AyuCD00 & READ & [X]Unspecified human immunodeficiency virus [HIV] disease & Definite \\
\hline A789000 & READ & HIV disease resulting in mycobacterial infection & Definite \\
\hline A789900 & READ & HIV disease resulting in lymphoid interstitial pneumonitis & Definite \\
\hline AyuCB00 & READ & [X]HIV disease result/haematological+immunologic abnorms,NEC & Definite \\
\hline R109.00 & READ & [D]Laboratory evidence of human immunodefiency virus [HIV] & Definite \\
\hline ZV01A00 & READ & [V]Asymptomatic human immunodeficency virus infection status & Definite \\
\hline 799MD & OXMIS & AIDS & Definite \\
\hline 799CA & OXMIS & AIDS CARRIER & Definite \\
\hline L1111PV & OXMIS & HIV ANTIBOBY TEST POSITIVE & Definite \\
\hline L7990A & OXMIS & ACQUIRED IMMUNE DEFICIENCY SYNDROME & Definite \\
\hline L 153P & OXMIS & HTVL-AIDS-III ANTIBODY TEST POSITIVE & Definite \\
\hline $43 \mathrm{~V} 1.00$ & READ & Absolute CD4 count & Ambiguous \\
\hline AyuD800 & READ & {$[\mathrm{X}]$ Retrovirus infections, not elsewhere classified } & Ambiguous \\
\hline AyuKM00 & READ & [X]Retrovirus/cause of diseases classified to other chapters & Ambiguous \\
\hline 43VE.00 & READ & CD4/CD8 ratio & Ambiguous \\
\hline A7y0100 & READ & Retrovirus as cause of diseases classified to other chapters & Ambiguous \\
\hline 43VH.00 & READ & Percentage CD4 count & Ambiguous \\
\hline $4 \mathrm{~J} 34.00$ & READ & HIV viral load & Ambiguous \\
\hline $4 \mathrm{~J} 35.00$ & READ & HIV p24 antigen level & Ambiguous \\
\hline $43 \mathrm{~h} 2.00$ & READ & HIV 1 PCR & Ambiguous \\
\hline $43 \mathrm{j} 7.00$ & READ & HIV 1 nucleic acid detection & Ambiguous \\
\hline $43 V_{0} .00$ & READ & Absolute CD4 (T4 cells) count & Ambiguous \\
\hline $43 \mathrm{Vp} .00$ & READ & Percentage CD4 (T4 cells) count & Ambiguous \\
\hline
\end{tabular}




\section{Reference List}

(1) The UK Collaborative Group for HIV and STI Surveillance. Testing Times. HIV and other Sexually Transmitted Infections in the United Kingdom:2007. London: Health Protection Agency, Centre for Infections.; 2007.

(2) Cartledge JD, Weller IV. Shared care in HIV and AIDS: shifting care or shifting costs? Journal of the Royal College of Physicians of London 1998 Jul;32(4):3769 .

(3) Singh S. Personal Communication. 2009.

(4) Smith S, Robinson J, Hollyer J, Bhatt R, Ash S, Shaunak S. Combining specialist and primary health care teams for HIV positive patients: retrospective and prospective studies. BMJ 1996 Feb 17;312(7028):416-20.

(5) Chadborn TR, Delpech VC, Sabin CA, Sinka K, Evans BG. The late diagnosis and consequent short-term mortality of HIV-infected heterosexuals (England and Wales, 2000-2004). AIDS 2006 Nov 28;20(18):2371-9.

(6) NHS Executive. Reducing mother to baby transmission of HIV. London: Department of Health; 2008. Report No.: HSC 1999/183.

(7) Mercey D. Antenatal HIV testing. BMJ 1998 Jan 24;316(7127):241-2.

(8) Jones S, Sadler T, Low N, Blott M, Welch J. Does uptake of antenatal HIV testing depend on the individual midwife? Cross sectional study. BMJ 1998 Jan 24;316(7127):272-3.

(9) Townsend CL, Cliffe S, Tookey PA. Uptake of antenatal HIV testing in the United Kingdom: 2000-2003. J Public Health 2006 Sep;28(3):248-52.

(10) British Assocation for HIV, British Association for Sexual Health and HIV, British Infection Society. UK National Guidelines for HIV Testing 2008. 2008 Sep.

(11) Chief Medical Officer Letter. Improving the detection and diagnosis of HIV on non-HIV specialities including primary care. Gateway reference no: 8519. 13th Sept 2007. 2007. London, Department of Health.

(12) Sudarshi D, Pao D, Murphy G, Parry J, Dean G, Fisher M. Missed opportunities for diagnosing primary HIV infection. Sexually Transmitted Infections 2008 Feb $1 ; 84(1): 14-6$.

(13) Sullivan AK, Curtis H, Sabin CA, Johnson MA. Newly diagnosed HIV infections: review in UK and Ireland. BMJ 2005 Jun 4;330(7503):1301-2. 
(14) Majeed A. Sources, uses, strengths and limitations of data collected in primary care in England. Health Statistics Quarterly (21):5-14, 2004.

(15) Department of Health NCfCaC. Read/ICD-10 joint training project: Read codes in use. 1997.

(16) Chadborn TR, McGarrigle CA, Waight PA, Fenton KA. Trends in, and determinants of, HIV testing at genitourinary medicine clinics and general practice in England, 1990-2000. Sexually Transmitted Infections 2004 Apr $1 ; 80(2): 145-50$.

(17) Health Protection Agency. Numbers Accessing HIV Care. Health Protection Agency 2007 [accessed 2007 Oct 12];Available from: URL: http://www.hpa.org.uk/infections/topics_az/hiv_and_sti/Stats/HIV/Care/default.ht $\underline{\mathrm{m}}$

(18) Sullivan AK, Curtis H, Sabin CA, Johnson MA. Newly diagnosed HIV infections: review in UK and Ireland. BMJ 2005 Jun 4;330(7503):1301-2.

(19) Gilbart VL, Dougan S, Sinka K, Evans BG. Late diagnosis of HIV infection among individuals with low, unrecognised or unacknowledged risks in England, Wales and Northern Ireland. AIDS Care 2006 Feb;18(2):133-9.

(20) Anderson J, Doyal L. Women from Africa living with HIV in London: a descriptive study. AIDS Care 2004 Jan;16(1):95-105.

(21) Madge S, Olaitan A, Mocroft A, Phillips A, Johnson M. Access to medical care one year prior to diagnosis in 100 HIV-positive women. Fam Pract 1997 Jun;14(3):255-7.

(22) Department of Health. The national strategy for sexual health and HIV. London: Department of Health; 2001 Jul.

(23) Donaldson L. Improving the detection and diagnosis of HIV in non-HIV specialties including primary care. London: Department of Health; 2007.

(24) Branson B, Handsfield HH, Lampe MA, Janssen RS, Taylor A, Lyss S, et al. Revised Recommendations for HIV Testing of Adults, Adolescents, and Pregnant Women in Health-Care Settings. MMWR 2006;55((RR14)):1-17.

(25) Sullivan AK, Curtis H, Sabin CA, Johnson MA. Newly diagnosed HIV infections: review in UK and Ireland. BMJ 2005 Jun 4;330(7503):1301-2. 